\title{
Plasticidade das imagens audiovisuais no espaço acústico- ressonante do cinema
}

\section{Irene de Araújo Machado}

\section{Resumo}

0 presente ensaio examina a relação entre espaço e comunicação, nos meios audiovisuais, marcada pelo domínio do regime escópico em detrimento dos objetos sonoros. Reivindica-se o realinhamento do papel do som na definição audiovisual da cultura, de modo a reposicionar a importância da dimensão sonoroacústica. Para isso, a hipótese de fundo reconhece que 0 cinema tem um papel decisivo na renovação da relação do som com o ruído, sobretudo no que diz respeito à consolidação do espaço acústico-ressonante criado pelos meios elétricos. Por conseguinte, entende que matérias sonoras são tão determinantes das imagens audiovisuais quanto a visualidade, como se pode averiguar nas análises filmicas comparativas. Espera-se, assim, resgatar o legado das culturas acústicas, agora reprocessadas em termos de experiência audiovisual de caráter eletrônico-digital.

\section{Palavras-Chave}

Cultura audiovisual. Espaço acústico. Ressonância.

\section{Irene de Araújo Machado I irenear@usp.br}

Professora Livre-Docente em Ciências da Comunicação pela Universidade de São Paulo - USP, Brasil. Vice-Coordenadora do Programa em Meios e Processos Audiovisuais da USP e editora científica de Significação - Revista de Cultura Audiovisual. Pesquisadora do CNPq (PQ-1D).

\section{Introdução}

A redescoberta do sensorium no contexto de expansão dos meios eletrônicos audiovisuais, como o cinema, tem multiplicado não apenas a compreensão das formas sensíveis da produção audiovisual como também 0 arco de temas e problemas sobre a produção de sentido - centro dos debates em áreas distintas de conhecimento na segunda metade do século XX. Se as investigações subsequentes acrescentam uma perspectiva analítica a esses debates, esta só pode ser a que entende as experiências sensoriais como intercâmbio dos sentidos e de seus efeitos cada vez mais irreverentes. Sinais dessa irreverência são notados nas experiências estéticas audiovisuais iniciadas no cinema, ampliadas pelo vídeo e pelos processos digitais, quando o registro em película cede lugar ao processamento eletrônico das imagens sonoras, visuais e cinéticas. Nasce, então, um espaço cinemático de inter-relações sensoriais e de projeção de signos, em que os efeitos de sentidos dos meios eletrônicos introduzem variantes inusitadas na experiência perceptual e cognitiva, 
como as emanações que se concentram no corpo humano, desafiando a uma redescoberta do sensório nesse espaço cinemático de convívio.

0 presente ensaio propõe enfrentar o desafio de compreender como as imagens cinéticas audiovisuais geram espaços sensoriais de sentidos no vasto campo de sua manifestação. Para isso, examina os processos de produção das imagens audiovisuais do cinema criadores de sentidos plásticos, emergentes e irreverentes. Interessa-nos particularmente o movimento cinemático construído pela reverberação acústica, que se encarrega de produzir uma gestualidade tátil e de projeção luz, que vimos dimensionados na composição dos filmes analisados ${ }^{1}$. Ondas de luz, de sons, de movimentos sensoriais encarregam-se de produzir a plasticidade das imagens audiovisuais com recursos elétrico-eletrônicos. Forma-se um espaço cinemático acústico ressonante, marcado pela irreverência de intercâmbios livres de qualquer especialização e dominância.

\section{Hipóteses de estudo em um campo em expansão}

0 quadro dos estudos teóricos centrados na análise de produções audiovisuais dimensionadas pela exploração sensorial reúne diversas abordagens. Isso se dá à revelia das dominantes conceituais, que insistem em limitar o campo da imagem-em-movimento apenas à visualidade, ignorando os vínculos da imagem audiovisual com o espaço cinemático reconfigurado pela ressonância dos processos eletrônicos.

Se 0 objetivo é compreender 0 espaço cinemático resultante dos processos elétrico-eletrônicos que o cinema desenvolveu como imagem audiovisual e cinética, há que se retomar o debate partindo das formulações que, desde Marshall McLuhan, foram observadas no campo da história da cultura por meio de estudos comparativos (McLUHAN, 1969; 1977; 1989). No foco desse debate, está a revalorização de práticas culturais interativas que, além de problematizar o "regime escópico" centralizado na imagem visual (MIDOLO, 2007, p. 11), permitiu dimensionar formas de convívio que estimulam diferentes regiões dos sentidos. É nesse ambiente que se situam as experiências em que a visualidade, o movimento e a tatilidade das imagens animadas são conjugadas como vibração de formas luminosas e ondas sonoras - hipótese de fundo deste ensaio.

Nesse sentido, ao considerar o espaço acústico ressonante como objeto de estudo privilegiado da cultura audiovisual eletrônica, espera-se dialogar com as investigações que redescobriram o sensorium e reavivaram uma tradição de pensamento que, desde Aristóteles, reconhece 
a existência de um sensus communis situado no corpo. Atos de ascese de rituais doutrinários medievais ou experiências e performances sensoriais estimuladas pelos meios audiovisuais eletrônicos são os extremos do que se encontra em estudos de tais práticas que constituem eixos de uma história revisitada por estudos distintos (CRARY, J., 1992; DELEUZE, G., 2005; DOANE, M.A., 2002; EISENSTEIN, S. 1975; HANSEN, M.B., 2012; McLUHAN, Erick, 2015; SHAVIRO, S., 2015; SOBCHACK, V., 2004; SODRÉ, M., 2006; XAVIER, I., 1983; MACHAD0, 2011). No espaço cinemático ressonante, é o corpo que responde pelo intercâmbio dos sentidos em que uns ressoam sobre os outros (SOBCHACK, 2004, p. 60).

No exame de sua hipótese fundamental, o presente ensaio considera que 0 cinema desempenhou papel decisivo não apenas na constituição de um espaço audiovisual eletrônico, disseminado no século XX (DRUCKREY, 1996; CHARNEY; SCHWARTZ, 2001), como também se tornou um campo experimental para os desígnios de renovação da relação do som com o ruído do entorno cultural em contínua transformação. Ao constituir a matéria sonora como outra dimensão da imagem no espaço elétrico da tela, o cinema confere ao som 0 estatuto de meio capaz de transformar experiências audiovisuais em fatos culturais.

Para examinar a propriedade de tal hipótese, o trabalho se desenvolve no campo da análise filmica, destacando obras representativas da constituição do espaço sonoro do ponto de vista das interações acústico-ressonantes que, na cultura audiovisual, decorrem da exploração da eletricidade e dos meios de comunicação. Desdobram-se daí as inferências que entendem os sistemas culturais como processos sígnicos que agem por cooperação, longe de privilegiar um sistema em detrimento de outros. Valendo-se do dispositivo de tradução, os sistemas organizados movimentam relações das quais emergem formas de distintas tradições culturais. Com isso, quer-se dizer que, diferentemente da supervalorização do olho e da visão no regime escópico, o processo audiovisual introduzido pelos meios eletrônicos estimula o regime (ci) sinestésico em que os sentidos e as percepções são traduzidos em corpos humanos e em suas extensões elétricas - tais como as telas, os equipamentos sonoros - como um complexo de interações e relações de sinestesias.

Tal hipótese ganhou desenvolvimento a partir das realizações fílmicas e teóricas de Sergei Eisenstein, que se expandiram e alcançaram outras esferas de práticas e entendimento. Isso é 0 que podemos afirmar a partir de estudos, como os de Vivien Sobchack, em sua compreensão do campo sensorial do corpo cinemático como uma manifestação de cenestesia. Por meio do neologismo «cinesthetic», Sobchack avançou na compreensão do cinema como cinese (de kinesis, movimento) e como sinestesia (conjugação de sentidos) em direção ao domínio sensorial do corpo humano no espaço. Considerou "dois termos científicos que designam estruturas particulares 
e condições do sensório humano, a saber:

«synaesthesia» (sinestesia) e «coenaesthesia» (cenestesia)" (SOBCHACK, 2004, p. 67). Com isso examinou como o cinema opera a cenestesia ao dimensionar a atuação do corpo como consciência do seu entorno, expressa em termos de posição, movimento, postura.

Observa-se que aquilo que Eisenstein examinou como manifestações do discurso interior, Sobchak desenvolve em termos de uma visada mais ampla da propriocepção. Evidencia, assim, a consciência segundo a qual os sentidos não se constituem isoladamente nem se manifestam como unidades discretas, mas funcionam como "superfícies de contato", segundo a formulação de Elena del Rio (DEL RIO, p. 101 apud SOBCHACK, 2004, p. 65). Isso nos leva a vislumbrar uma porosidade sensorial que sustentada pelos efeitos de sentidos estimulados pelos meios. Nesse ponto, somos levados a compreender as inflecções sensoriais reproduzidas pelas imagens audiovisuais como sistemas semióticos dotados de mecanismos culturais de tradução que, nos mais diferentes processos interativos, funcionam como canais pelos quais os diferentes sistemas interferem uns nos outros.

Do ponto de vista dos sistemas semióticos da cultura, os processos audiovisuais cumprem os desígnios dos demais processos interativos da cultura e, por isso, não podem ser considerados como estruturas acabadas, mas sim como modelos em curso. Tal raciocínio alinha-se ao pensamento semiótico de Iúri Lótman (1990), para quem os mecanismos de tradução sensorial desenvolvem, nas linguagens, diferentes modelizações onde as interferências sensoriais são evidências.

Se a audiovisuailidade criada pelo cinema movimenta signos do universo sensorial humano e os traduz por meio de relações de sentidos em efeitos encadeados, o espaço cinemático ressonante pode ser considerado uma premissa do processo cultural de tradução intersemiótica. Tal é 0 caminho investigativo a ser cumprido a partir das hipóteses apresentadas.

\section{Ondas que se movimentam no espaço cultural}

Tendo no horizonte de referência a noção de porosidade semiótica como mecanismo construtivo da "superfície de contato" do espaço cinemático, examinemos a ressonância advinda da tradução de diferentes constituintes sensoriais. De antemão há de se relativizar a definição da ressonância apenas como resultado da capacidade de emitir vibrações. Se é fato que o som produz vibração, não é fantasia afirmar que, para além de ondas ruidosas, o som só se realiza como dimensão sensorial quando se torna «ouvido». Por conseguinte, a emissão sonora da condição da vibração só se completa na esfera da escuta.

Nenhum som constitui-se enquanto matéria sonora sem escuta, o que vincula, do ponto de vista humano, a condição sonora às experiências 
de convívio. Por conseguinte, a invisibilidade de uma vibração sonora só se constitui como experiência ao envolver e ser traduzida sensorialmente por um corpo do qual se torna parte. Tal envolvimento e sensorialidade é o que se observa na imagem audiovisual: corpo visual de um envolvimento ressonante.

Em seus estudos de filosofia da voz e da escuta segundo a fenomenologia da voz, Don Ihde (1990; 2007) trata do fenômeno da ressonância como vibração que se movimenta como envolvimento de emissão e de escuta - fora, portanto, da noção distintiva de polos oponentes. Para isso, considera como matéria sonora a emanação de um aparelho fonador ao processar o gesto que resulta na respiração. Ao se manifestar no corpo que respira, a vibração sonora não apenas é emissão do corpo, mas também escuta, e o ouvido, um órgão sensorial produtor de uma superfície de contato. Um existe em função do outro, o que revela a condição acústica da ressonância. Infere-se daí que, do corpo que respira, emerge um espaço acústico ressonante em que 0 som vibra e envolve na escuta. Trata-se de um entendimento que situa a propriedade da experiência humana no mundo fenomênico e vivencial.

0s quadros delineados nessas linhas reposicionam práticas definidoras de comportamentos culturais que a história da cultura relata ao recuperar as características das culturas orais acústicas (GOODY; WATT, 1988; LOPES, 2001; McLUHAN, 1977; ONG, 1967, 1971, 1977). Ao situar na base das interações e trocas as práticas de uma comunicação que vai da boca diretamente ao ouvido, criando o circuito oral-aural, tais culturas interagem graças ao envolvimento, pelo som, em atos de interlocução e de presença coletiva, como examinou Walter Ong em seus estudos (ONG, 1967; 1971; 1977; 1998). Nessas práticas, o meio de comunicação do circuito oral-aural é também responsável pela produção dos espaços de envolvimento e de convívio. E esse é um legado histórico-cultural cujo regime sensorial é 0 da vibração que produz ondas sonoras de envolvimento, de presença, de escuta mobilizadora de diálogos. Para 0ng, realizações como essas transformam 0 circuito oral-aural no legado indelével da cultura audiovisual desenvolvida pelos meios eletrônicos (ONG, 1998) a partir da tecnologia de gravação e reprodução sonora, em que coube à voz tornar-se 0 centro referencial de envolvimento num espaço acústico ressonante.

Delineia-se aqui um problema que indaga sobre a condição, a natureza e 0 papel da produção sonoro-acústica na cultura audiovisual. Examinálo atende demandas de reposicionamento do lugar da dimensão sonora nessa cultura. Se, por um lado, trata-se de reconhecer o potencial interativo da matéria sonora, por outro, colocase a necessidade de uma revisão do campo de forças em que o regime escópico reina soberano, supostamente desvinculado de tudo que emerge como dimensão oral-aural.

Do ponto de vista de sua potência, a cultura audiovisual já deu mostras suficientes de 
ampliação de suas esferas de reverberação não apenas pela variedade de fontes sonoras que produz, como também pelo espaço ressonante com diferentes frequências e intensidades de escuta sem a qual a condição acústica simplesmente não aconteceria. Teoricamente, tais mudanças foram objeto de formulações que constituem, senão a história, pelo menos as articulações conceituais da nova episteme cultural oral-aural, que historiadores da cultura definem como atributo e marco histórico das culturas orais acústicas. É hora de mirar nosso problema de frente.

Não é por falta de estudos que os signos sonoroacústicos continuam a ser tratados como um mero apêndice - um mero prefixo na palavra «audiovisual», ou um parêntese nos estudos da imagem (som). Nas artes, nas ciências, na comunicação e na cultura desenvolvem-se investigações que não podem ser ignoradas quando se trata de reposicionar as linhas de força do regime escópico de modo a valorizar o som como forma geradora de cultura (BERENDT, 1988; BULL; BACK, 2003; DROBNIK, 2004; ERLMANN, 2004, 2010; McLUHAN, 1977, 1989; STERNE, 2003).

Antes mesmo de a eletricidade dominar 0 espaço ressonante com meios, vale considerar o alvorecer de um cenário cultural acústico na variada gama de estesias emergentes no entorno urbano. Introduzidos pela indústria, ruídos mecânicos, chaminés fumegantes, sirenes e conglomerados de pessoas em deslocamentos definem a própria condição urbana das cidades. Inicia-se aí uma escalada de transformações responsáveis por mudanças sensoriais de recepção sonora como, por exemplo, as torres e redes de transmissão, que modificaram as cidades em seus espaços de circulação, transporte, transmissão e, sobretudo, de informação, como Friedrich Kittler (2006) investigou em seus estudos. Graças a esse emaranhado de os fios, linhas e cabos elétricos, a presença é transformada e vozes são amplificadas, vencendo distâncias, mudando o caráter da comunicação oral-aural, ainda que a transmissão por meio dos circuitos seja silenciosa.

Na ruidosa ambiência de máquinas, ônibus, automóveis, buzinas, rádio, telefone e produtos sonoros correlatos, a contínua renovação das fontes sonoras e perceptuais de sons e ruídos torna-se vertiginosa. Compreendê-la tornou-se um dos desafios da cultura audiovisual centrada na conjugação da audiovisualidade em circuitos eletrônico-digitais que potencializaram e redimensionaram o circuito oral-aural. Esse é um desafio que sempre é preterido em face do primado da imagem visual da cultura pictórica, que se consagrou pelo registro de signos em superfícies (FLUSSER, 2007; McLUHAN, 1977).

Coube a McLuhan delinear os caminhos analíticos do ambiente da produção tecnológica geradora daquilo que ele julgou constituir 0 centro produtivo da paisagem urbano-industrial responsável pelo espaço acústico ressonante 
Figuras 1 e 2: Fotomontagem e Stills de transmissão em vídeo para televisão

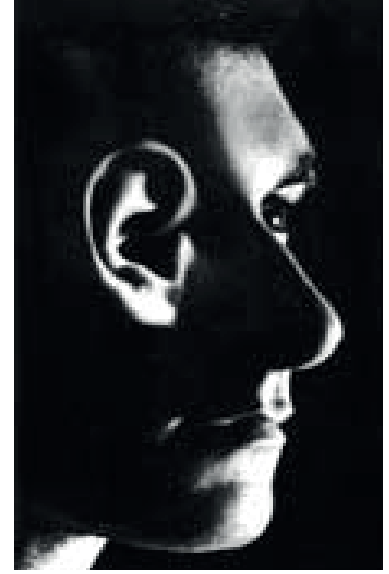

Fotomontagem Olhoouvido (1969).

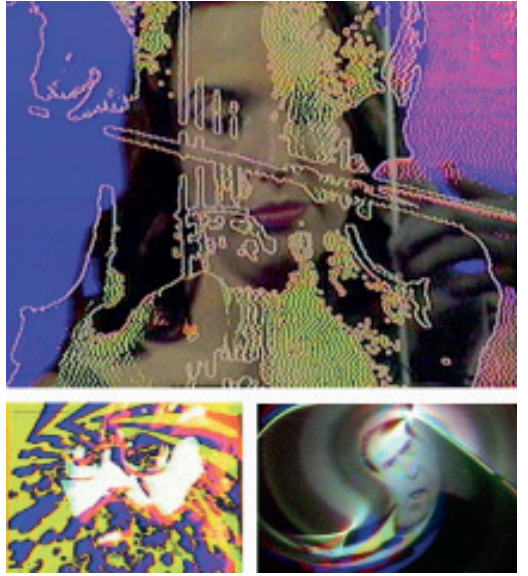

Global Groove. Nam June Paik, 1973 *

* Fonte do vídeo Global Groove: http://www.cram.com/flashcards/arthist-final-2-8608106. Acesso em 27/10/2017.

(McLUHAN, 1996). Nesse espaço, observou que as renovações obedecem a forças cada vez mais invisíveis e cada vez mais radicalmente mobilizadoras de ambientes com distintos gradientes de reverberação, a ponto de desenvolverem uma complexa paisagem dotada de plasticidades, cuja escalada redimensionou o espaço acústico-ressonante num complexo soundscape - como modernamente o espaço acústico-ressonante é dimensionado. Nele, 0 singelo circuito oral-aural da global village dilatou-se e tornou-se um espaço invisível de reverberações e ressonâncias invisíveis, multidirecionais, onipresentes.

Traduzidas como global groove pelo videoartista Nam June Paik (1973), o espaço acústico ressonante da global village não distingue instrumentos eletrônicos de produção sonora, de percussão e de modificação do ruído dos equipamentos de produção audiovisual. Experimenta, assim, aquilo que McLuhan vislumbrara ao prever que a grande extensão do olho seria o ouvido, que ficou traduzida na metáfora gráfica do olhoouvido desenhada por Quentin Fiore (McLUHAN; FIORE, 1969, p. 121).

A metáfora do olhoouvido apenas procura redimensionar a condição de similaridade entre os dois sentidos, como considerou Lucia Santaella, ao afirmar que: "Olho e ouvido captam ondas, luminosas o primeiro, sonoras o segundo. Trata-se aí de uma realidade física-fisiológica. Contudo, a diferença entre eles evidencia-se no tipo de onda que é captada" (SANTAELLA, 2016, p. 199).

A dimensão sensorial operada em espaços ressonantes dessa configuração pode ser também 
entendido do ponto de vista dos processos de "embodiment" formulados por Vivien Sobchack. Graças à condição de invisibilidade de muitas das manifestações sensoriais, 0 corpo e sua capacidade de traduzir sensações - de encarnálas - tornam-se campo de forças nos quais "nossa capacidade de ver, ouvir, tocar, cheirar, provar" como também de "sentir proprioceptivamente nosso peso, dimensões, gravidade e movimento no mundo" ganham concretude (SOBCHACK, 2004, p. 60 ), configurando-se como "dimensões subjetivas e objetivas da existência encarnada" (SOBCHACK, 2004, p. 4)

Aquilo que se observa nas imagens animadas do cinema pode ser entendido no movimento cenestésico - no sentido formulado por Sobchack - mais preciso e alcançar, por exemplo, o campo sonoro de ruídos ambientais ou culturais. A experiência da música em determinadas culturas converte-se numa forte referência nesse momento, sobretudo pelo uso do corpo como fonte sonora e manifestação encarnada de escuta.

Seja como expansão sensorial, seja como reverberação em traduções como os soundscapes ou groove eternizados pelas guitarras eletrônicas de bandas de rock, em performances de música eletro-acústica ou pelo $d u b$ jamaicano com seus desdobramentos musicais e performáticos, 0 fato é que a cultura audiovisual estabeleceu fortes relações de parentescos com as estesias culturais propiciadas por tais realizações. 0 cinema nunca deixou de se alimentar de experiências culturais como essas, nem mesmo em sua fase silenciosa. Logo, reduzir o universo acústico à visualidade é ignorar a onda elétrica que se movimenta no espaço cultural. Afinal, pervasividade e ubiquidade - características atribuídas com exclusividade às imagens visuais digitais - constituem a natureza da reverberação e, consequentemente, do som. Um $d u b$ jamaicano já operava nessa frequência nos idos dos anos de 1950, quando o global groove eletrificou a paisagem urbana do século XX, traduzindo ondas e ritmos que culturas distintas desenvolvem nos circuitos de suas práticas renovando as relações no movimento da cultura. Por essa época a cultura audiovisual de meios de comunicação ganhava os espaços culturais com seus soundscapes.

Se a música tornou-se habitat elementar de um ecossistema urbano, a experiência audiovisual do cinema não foi menos expressiva. Ao converter o som gravado em sinais ópticos registrados na película, o cinema criou a sincronia de som e imagem potencializando a noção de ritmo na montagem de planos, seu código audiovisual elementar. Com isso, imprimiu na película a condição audiovisual. 0 tão citado hibridismo do cinema, tributário de sua ligação com 0 teatro, a literatura e a pintura, articula-se em outra esfera, aquela dos movimentos e cadências de ritmos musicais, jogos entoativos de vozes em contraponto com diferentes fontes sonoras.

Por conseguinte, pode-se inferir que, se 0 objeto de estudo das culturas orais acústicas foram 
as práticas culturais de voz e escuta no e pelo corpo, o objeto de estudo da cultura audiovisual só poderia focar as práticas de reverberação sonora, visual, acústica, típicas do meio elétrico e da audiovisualidade nascente também no e pelo corpo cinemático (SHAVIRO, 2015) - práticas que as tradições das experiências dos reverb ou dubs jamaicanos conjugam como continuidades.

0 raciocínio esboçado nessas linhas sintetiza um esforço em realinhar os eventos cruzados da experiência audiovisual na cultura contemporânea de modo a valorizar a natureza sensorial de suas formas. Trata-se de uma demanda que justifica e sustenta a realização de investigações no campo da semiótica da cultura, abrindo caminho para se explorar os argumentos centrais desse ensaio.

\section{Emergência da imagem acústica no uso da câmera como sonar ${ }^{2}$}

\author{
Comecemos por explicitar a noção de "câmera \\ como sonar". Trata-se de uma expressão que foi \\ usada metaforicamente por uma testemunha, \\ a senhora Violeta Berrios no filme de Patrício \\ Guzman Nostalgia da luz (2010), conforme \\ examinamos em outro estudo (MACHADO, \\ 2016, p. 1-16). Guiada por sua necessidade de \\ descobrir, nas ossadas enterradas no deserto de \\ Atacama, o corpo de seu Mário, desaparecido
}

durante a ditadura Pinochet, Berrios imaginava um dia em que as câmeras pudessem estar não nos telescópios, mas também nos aparelhos de captação dos sons nas entranhas da terra. 0 sonho de Violeta Berrios era que os sonares penetrassem as entranhas da terra de modo a alcançar os seres iluminados escondidos no mundo subterrâneo. Ela desconhecia os investimentos em curso nessa área.

Ao uso metafórico dos sonares, associamos, por um lado, as possibilidades exploradas pelas transformações da gravação sonora em registro magnético em registro óptico, que é devolvida como imagem audiovisual e, por outro, as possibilidades de explorar a trama de sons, ruídos, músicas em canais e fontes transmissoras diversificadas. Segundo Fernando M. da Costa, Assistimos, ao longo do século XX, à ampliação
da faixa de frequências audíveis, não em nossos
ouvidos diretamente, já que não são capazes
disso, mas dos usos variados de frequências
abaixo e acima do limite da audição humana,
para procedimentos científicos que fazem cada
vez mais parte de nosso cotidiano: infrassons,
ultrassons (COSTA, 2017, p. 28).

Além das expansões que contam com 0 desempenho das câmeras audiovisuais, agora em sua versão digital, há que se considerar que a noção de sonar também não se desvincula do no filme Nostalgia da luz (2010), conforme examinamos em outro estudo (MACHAD0, 2016, p. 12-3). 0 sonho mitológico de Violeta Berrios era que os sonares penetrassem as entranhas da terra de modo a alcançar os seres iluminados escondidos no mundo subterrâneo. 
sistema técnico de reverberação que, numa sala de cinema, por exemplo, explora o sistema de som surround quando a variedade de canais independentes é reproduzida pelas fontes de áudio dimensionadas na sala escura. Com isso, a câmera-sonar não desempenha apenas a tarefa de registrar como também de reproduzir e equalizar sons capazes de transformar um filme numa composição musical - caso do filme de Godfrey Reggio.

Do ponto de vista da cultura audiovisual, em que se desenvolveu o espaço acústicoressonante do meio elétrico, as formas sensoriais que se expandiram sob forma de instrumentos de captação da luz e de som são produções de câmeras e gravadores - mediadores fundamentais da operação que desencadeou a escalada modelizante do processo audiovisual. Devido a esses dispositivos mecânicos e elétricos, a expansão do circuito oral-aural pode ser redimensionada em sua tradução cultural. A importância dos dispositivos no processo tradutório da cultura justifica não apenas o caráter semiótico dos sistemas como também os mecanismos da transformação de um modus operandi em outro. Ao processo de tradução operado por um dispositivo, para transformar um dado modelo em outro, os engenheiros denominaram transdução. Entendem, assim, que um modelo derivado de uma forma de energia pode ser transformado em outro com a transferência de informação ou simplesmente transdução.
Foi no campo da eletricidade que se forjou 0 conceito de transdução ante a necessidade de designar os processos de transferência de energia operada por um transdutor capaz de transformar uma forma de energia em algo distinto (SEIÇA, 2017). Na comunicação, a transdução é observada no âmbito da transformação da informação pelos meios que produzem modificação entre input e output, alterando a natureza do fenômeno (SEBEOK, 1996). 0 cinematógrafo opera como um transdutor que, ao projetar a luz capturada fotoquimicamente, configura eletricamente formas luminosas de movimento e sonoridade. Situa-se, pois, no alinhamento dos transdutores aprimorados pelas tecnologias de reprodução sonora-acústica que, segundo Jonathan Sterne, tomaram o próprio ouvido como transdutor (STERNE, 2003, p. 22).

Se 0 ouvido funciona como transdutor, as ondas sonoras propagadas não seguem simplesmente impulsos sem nenhuma mediação. Sons da voz humana, de animais em seu ecossistema, de movimentos da água ou de astros - enfim, ruídos mecânicos da paisagem urbana -, todos, indistintamente, são suscetíveis de mediação para serem percebidos acusticamente como processos significantes. Enquanto a propagação reproduz um comportamento que manifesta propriedade da onda sonora, a percepção acústica implica uma capacidade de produção de sentido. Assim como os olhos apreendem sinais luminosos e produzem imagem visual, 
os sons percebem as ondas em seus fluxos de intensidades, timbres e frequências. Entre imagem visual e imagem acústica, existe tão somente uma diferença de qualidade sensorial, o que constitui um alerta para a consagração equivocada de uma dominante sensorial sobre outra, caso da celebração da visualidade no signo audiovisual em detrimento se sua constituição cinético-sonoro-acústica.

A capacidade de 0 cinema transformar sinais luminosos em imagem visual ou sonora evidencia a competência de operar a transdução não apenas no que diz respeito à produção de imagens, mas também ao funcionamento da câmera. A possibilidade de a câmera ser usada como sonar se deve também à operação de transdução. 0 filme de Patrício Guzman Nostalgia da luz (2010) reporta-se ao uso da câmera como sonar. Num depoimento comovente, uma das mulheres que prestam depoimentos ao cineasta, Violeta Berrios, declara seu sonho de que, um dia, os cientistas possam utilizar suas câmeras como sonares, penetrando nas entranhas da terra de modo a alcançar os seres iluminados escondidos no mundo subterrâneo.

Apesar do uso "metafórico" dos sonares, o raciocínio de Berrios vislumbrou as realizações do uso das câmeras e dos aparelhos de ultra e infrassom, que nos levou a considerar o uso da câmera de cinema como sonar. 0 mais evidente uso da câmera como sonar pode ser observado na incorporação e no aprimoramento dos canais de gravação que, na projeção, deslocam-se da tela para os espaços das salas de cinema. 0 som surround produz, assim, o envolvimento entre os corpos presentes naquele espaço acústico ressonante. Trata-se de uma sofisticada tecnologia que o cinema silencioso não pode realizar, mas nem por isso deixou de propor hipóteses e construir alternativas por meio de procedimentos plásticos.

Dentre os diferentes realizadores que contribuíram para tal empreendimento plástico, Dziga Viértov coloca-se num lugar privilegiado. Em seu clássico O homem com câmera (1929), transformou as imagens visuais colhidas de improviso por sua câmera em "comunicação cinemática", imprimindo à articulação de planos e sequências uma dimensão acústica que é percebida como movimento rítmico, uma vez que 0 cinema não dispunha de condições de gravação sonora magnética na película fotoquímica. Nada impediu o cineasta de explorar a dimensão acústica do ponto de vista da onda que se propaga, reverbera e organiza o movimento acústico como manifestação semântica.

Na sonolência das primeiras horas do dia que desperta, apenas comparecem os primeiros movimentos da paisagem: movimentação no interior das casas, lojas e cidades. Portas que se abrem, ônibus que passam cada vez em maior quantidade, pessoas que se deslocam formando pequenas aglomerações. 0 ritmo 
caminha num crescendo, como as tomadas em que aparecem 0 início da sessão de cinema, que mostra não só as pessoas chegando e ocupando seus assentos, como também a orquestra posicionada para a performance de acompanhamento da exibição. A música inicia quando o projetor dispara e os pratos conclamam os instrumentos a vibrarem suas cordas, sopros e tambores. Tão logo a "música" avança, o homem com sua câmera sai em busca dos registros cinemáticos. 0 dia e 0 filme iniciam num ritmo crescente de intensidades e estímulos visuais e sonoros, ainda que não sejam ouvidos.

Experiência mais ousada foi realizada pouco depois, quando Viértov compôs a partitura de um filme sinfônico: Entuziazm, Sinfonia Donbassa (1930), sua primeira experiência na realização de um filme sonoro. 0 filme segue a partitura; logo, há um deslocamento da espacialidade: em vez de concentrar o som nos diálogos de personagens, Viértov distribui os materiais sonoros das máquinas industriais, do ambiente de trabalho, do entorno e desloca a leitura do filme para o conjunto da tela. Articulados com os ruídos urbanos, alguns cânticos, sons de sinos e um aglomerado de cacofonias, 0 tecido sonoro torna-se um conjunto dissonante e assíncrono. Nem mesmo a sincronia entre som e visualidade é mantida. Com isso, o filme confirma a estrutura composicional de uma peça sinfônica constituída por quatro movimentos: andante, allegro, presto, minueto, em função dos quais a trama se organiza (MICHELSON, 1984, p. 106-115). A contribuição desse filme para a constituição do espaço acústicoressonante, contudo, não é a estrutura, mas sim a espacialidade criada pelo tecido dissonante plasticamente construído de modo a descentralizar o som da voz e do diálogo, gerando uma leitura fílmica de escuta, não de visualização.

Na linha desse experimento, não há como não lembrar de uma realização de intensa potencialidade construtiva de ressonância espacializada. Trata-se do filme Terra em transe (1967), de Glauber Rocha. Nele, a espacialização do som encontrou uma expressão memorável concentrada na primeira sequência do filme.

Figura 3: Plano sequência de Terra em transe (1967), de Glauber Rocha.

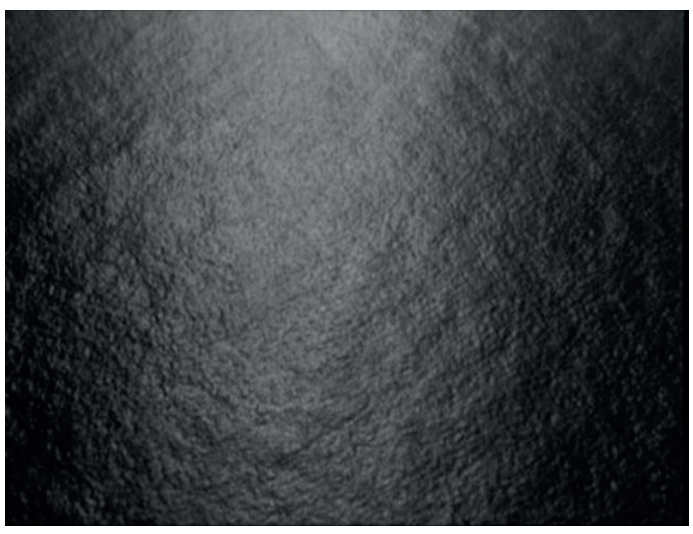

Fonte: http://caiana.caia.org.ar/template/caiana. php?pag=articles/article_2.php\&obj=246\&vol=9. Acesso: 27/10/2017. 
No plano sequência, a câmera se desloca sobre a amplitude do mar oceano até encontrar o solo de Eldorado. Enquanto vemos a câmera avançar sobre o Atlântico negro (GILROY, 2001), o canto de povos, certamente nossos ancestrais africanos, embala a trajetória de diferentes projeções de temporalidades. Se 0 mar corresponde à porção do espaço que conjuga, num único plano topográfico, geografias de terras distintas que já formaram um só continente, o canto traduz não o espaço fracionado, mas as temporalidades conjugadas de modo a alcançar memórias escondidas da cultura brasileira em suas raízes africanas, cujos fios continuam a desenhar tramas relacionais e a ecoar dissonâncias.

0 trabalho de Glauber cresce em importância pela operação transgressora na geração do fenômeno audiovisual, que aqui faz do fluxo transtemporal o denominador comum da imagem visual e acústica. Ao fazer ecoarem os cantos ancestrais no escoamento fluido do plano aéreo do oceano negro, a composição transgride o próprio processo técnico. Embora o som tenha sido transduzido em sinal óptico como realização técnica, a percepção sensorial e cognitiva opera como um sonar e alcança os sons no fluxo da imagem visual. A câmera torna-se sonar.

Quando a câmera exerce 0 papel de sonar, o caráter de fluxo das formas luminosas potencializa sua condição elétrica e ressonante - um reverb que faz emergir a sensação das temporalidades em diferentes propagações com tradução para signos audiovisuais.

\section{Reverberação de imagens em fluxos audiovisuais}

Na produção sonora-acústica, um reverb define o movimento do som que ecoa ao se constituir na propagação de uma onda. Ainda que a noção de uma voz ecoando possa ser mera repetição, a qualidade sonora da matéria acústica alcança diferentes frequências, o que significa que podem ocorrer variações e interferências ambientais. Nesse sentido, um eco pode produzir reverberações sujeitas a interferências e desvios, evidenciando respostas inesperadas dentro de uma mesma frequência sonora.

No circuito eletrônico, elabora-se algo semelhante na produção das imagens acústicas audiovisuais que se manifestam como imagens-fluxo. Sob forma de diferentes composições de luz, linhas, velocidades, tonalidades, timbres, as imagens-fluxo resultam de transdução de sons, movimentos, figuras que são reprocessadas de modo a resultar em gestos gráficos ressonantes. Em fluxo, as imagens visuais deixam-se dominar pelo princípio da reverberação sonoro-acústica, multiplicando suas formas escópicas. Prevalecem, assim, a simultaneidade, a instantaneidade, a descontinuidade - um ambiente moldado pelos padrões do circuito eletrônico que se retroalimentam da transformação da luz, do som, do movimento sob forma de ondas. Quando a imagem-fluxo se torna princípio de composição audiovisual, a matéria sonora é fonte de exploração de uma nova relação do som com 0 
ruído. Em filmes dessa natureza, a reverberação sonora transforma em instrumento tanto a composição rítmica quanto as mais distintas fontes sonoras.

Com a experiência de Viértov e Glauber no horizonte, passemos ao emblemático concerto de reverberação sonoro-acústica realizado pelo projeto experimental de longa duração, que resultou na trilogia quatsi, do cineasta Godfrey Reggio em parceria com 0 músico Philip Glass. Constituída pelos filmes: Koyaanisqatsi: vida em (des)equilíbrio (1983), Powaqqatsi: vida em transformação (1988) e Naqoyqatsi: a vida em guerra (2002), as produções exploram a radicalidade dos recursos eletrônicos tanto sonoros quanto visuais. Nas duas primeiras produções, 0 trabalho filmico combina edição de fotografia no ritmo da música de Glass. No último, finalizado mais de uma década depois, a montagem organiza imagens de arquivos visuais reprocessadas digitalmente junto com o som de composições de música instrumental em arquivos de ritmos variados e combinações de tradições musicais distantes.

A abertura é marcada pelos acordes de uma fanfarra que introduz um canto lírico entoando a palavra-título do filme: Naqoyqatsi, ao mesmo tempo em que o plano focaliza a tela de Pieter Bruegel, Torre de Babel (1563) em zoom out, dilatando um movimento centrípeto até perder 0 foco. 0 fluxo da voz em performance operística continua a entoar o canto, ressoando com o cello de Yo-Yo Ma de modo a estabelecer um contraponto lírico com a visualidade, tão dinâmico quanto dramático. A câmera se desloca para 0 interior de um edifício: uma estação abandonada e tomada por destroços de uma construção outrora imponente. 0 cello domina e dialoga com outros instrumentos e ruídos: sintetizadores, percussão de batidas metálicas, sinos tubulares, batimentos cardíacos, arpejos de violão, enquanto a câmera continua a perambular pelo edifício até alcançar o topo da construção num ângulo externo, iniciando a descida e tomando o edifício em contra-plongée, dissolvendo-o nas águas de um mar revolto processado digitalmente.

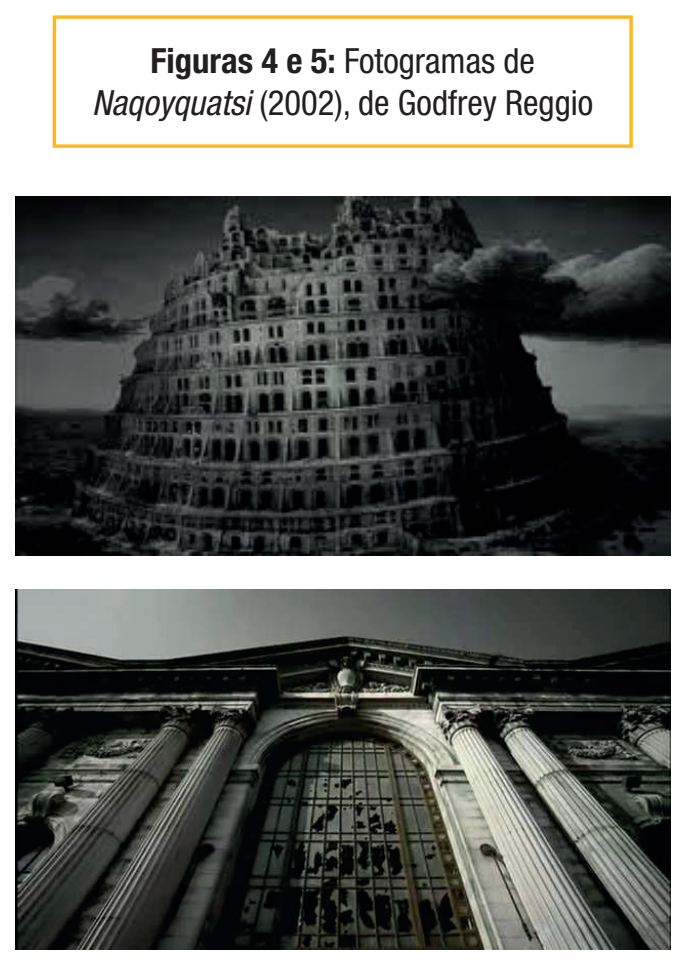

Fonte: http://staticmass.net/documentary/naqoyqatsidocumentary-2002-review/ Acesso: 03/06/2017.

Quando a tomada focaliza em contra-plongée, a totalidade da fachada, o percurso muda de direção e um movimento abrupto empurra o plano para trás e, na horizontalidade, a fachada se dissolve. 0 
trabalho de retroalimentação digital das imagens fotográficas e sonoras se inicia. 0 prelúdio ganha um novo contorno rítmico com a intensificação dos acordes, que seguem as transformações visuais da paisagem com recursos da computação gráfica. Raios cósmicos, cadeias de montanhas, nuvens, lagos e até pirâmides que brotam de um deserto computarizado começam a desenhar 0 conjunto audiovisual radicalmente virtual. Pessoas caminhando em imagens de negativos fotográficos formam vultos deformados em deslocamento, criando um contraponto com o som vibrante. Quando a imagem visual se rarefaz em linhas verticais, 0 canto retorna e a composição musical executa uma rápida sequência de percussão e cordas enquanto, entre as linhas de um código de barras animado (movie bar code), surgem tons vermelhos que projetam a palavra título do filme.

Figura 6: Fotograma da frase título do filme Naqoyquatsi, de Godfrey Reggio

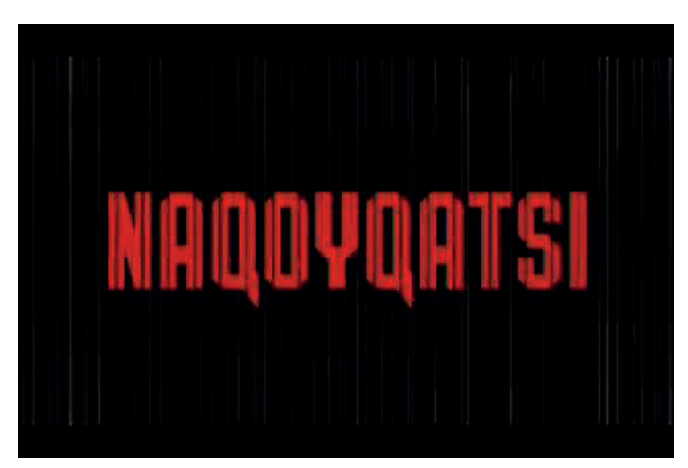

Fonte: https://www.youtube.com/watch?v=bGGrOYpHoFY Acesso: 12/11/2017
Ao sóbrio prelúdio se segue uma música em ritmo de dança que acompanha as evoluções da sequência composta por um fluxo vertiginoso de imagens de modo a refletir muito propriamente 0 "Primado dos números". Tem início uma gestualidade gráfica inusitada. Imagens audiovisuais dançam ao som de uma harpa de boca ${ }^{3}$ cujo ritmo marca uma batida na cadência do fluxo rápido das imagens em looping de formas elétricas faiscantes emitindo rastros luminosos: chuva de fótons? De elétrons? De raios cósmicos? Estelares? Seja do que for, o fluxo de imagens corre em convergência centrífuga, e seu núcleo compõe um contorno do sinal gráfico zero.

Figura 7: Fotograma da imagem-fluxo em Naqoyqatsi (2002), Godfrey Reggio.

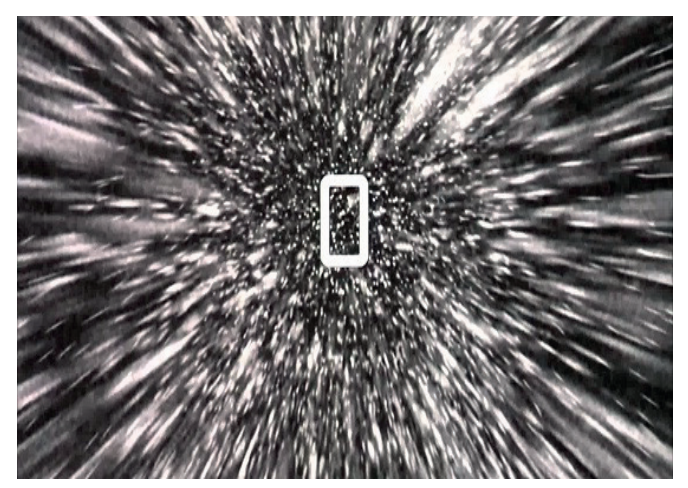

Fonte: http://incredible-tales.blogspot.com.br/ Acesso: 03/06/2017

Esse é apenas 0 algoritmo visual de um princípio composicional da sequência que recorre ao zoom de Ozark ou harpa de suco; é um instrumento lamelófono, que está na categoria de idiófilos arrancados: consiste em uma língua flexível de metal ou bambu ou cana anexada a uma armação. A língua / cana é colocada na boca do artista e arrancada com o dedo para produzir uma nota. Cada instrumento produz apenas um tom, com seus múltiplos (toques), embora os instrumentos de diferentes tamanhos ofereçam diferentes graus. Não existe um passo padrão. 
in para potencializar os conjuntos de Mandelbrot. Num fluxo que se retroalimenta, combinações randômicas de 0 e 1 , circuitos elétricos, mapas digitais progridem até chegar às imagens em negativo da marcha de soldados. A partir desse fluxo, percebe-se que as imagens conceituais da guerra não são as tradicionais cenas descritivas de combates, de troca de atividades tática ou de destruições. Com exceção da cena inicial da estação abandonada, a guerra aqui é construída em sua estratégica concepção digital: as formas gráficas de fórmulas matemáticas, operações geométricas, de diagramas.

Seguem-se as nove peças musicais que constituem os episódios do filme definindo seus movimentos, num total de onze composições. Além do Prelúdio Naqoyqatsi (1) e Primado dos números (2), temos: (3) Homem de massa, (4) Novo mundo, (5) Religião, (6) Tempo de mídia, (7) Velho mundo, (8) Tempo intenso, (9) Ponto cego, (10) Vivência desconhecida, (11) Definição.

Em Homem de massa, o reverb constrói-se como eixo temático da multiplicação randomizada, em que o corpo é submetido a um processo de transdução ao mesmo tempo em que é renderizado pela computação gráfica. Predominam os arquivos de imagens do corpo em ambientes aquáticos, espaços aéreos e imagens médicas de radiografias, retratados em atividades esportivas, movimentos celulares, atividades biomecânicas, deslocamentos de grandes massas de células, como espermatozoides, de pessoas, de pés em caminhadas, de bebês e, evidententemente, de manipulação genética do experimento realizado com a ovelha Dolly.
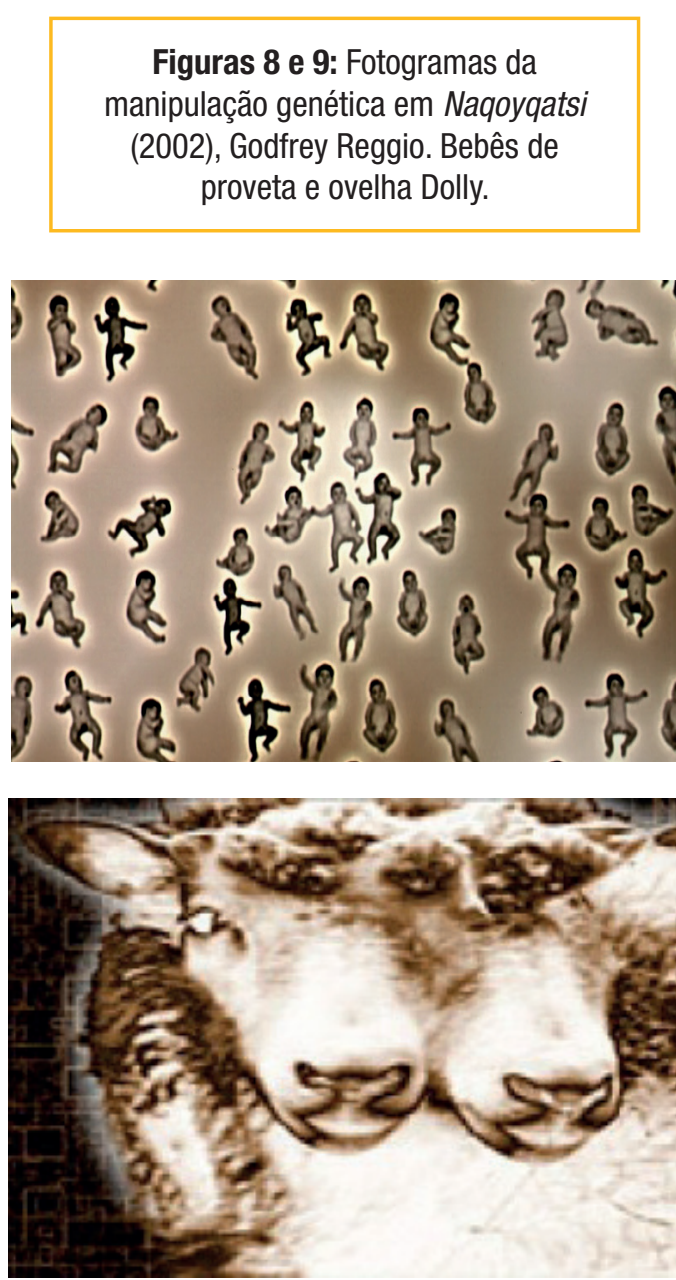

Fonte: http://www.dokument-festival.com/database/ movie/18126\%7CNaqoyqatsi. http://366filmesdeaz.blogspot.com.br/2016/12/ Acesso: 03/06/2017

Ainda que a música siga o leitmotiv da sequência, acompanhando a cadência dos movimentos, há momentos explosivos nos grandes saltos, corridas exaustantes de corpos e células. No final da sequência, o cello retorna e embala a singeleza de rostos sorridentes em cantos e vocalizações não sonorizadas, apenas gestualizadas, como 0 
contorno gráfico e traços das imagens visuais sombreadas em toda a sequência.

Na verdade, cria-se musicalmente um momento de transição para uma certa disforia sonora e visual que vai compor o episódio Novo mundo um interlúdio em que o cello é acompanhado por vibrafone - bem ao gosto das marimbas criadas pelo músico e criador de instrumentos, o brasileiro Marco Antônio Guimarães, do grupo Uakti.

Fluxos de imagens visuais reconstituem as glórias estadunidenses, como as maravilhas urbanas, as grandes disputas em campos esportivos, a vitória pela corrida espacial, os resultados positivos das bolsas de valores, as celebrações de Hollywood - todos espelhados nos olhos exaltantes de multidões basicamente masculinas. Somente uma intervenção com mais densidade orquestral marca esse episódio, que se inicia e se fecha visualmente com fumaças brancas esvanecendo no ar.

Figura 10: Fotograma de montagem de fumaça sobreposta à bandeira Americana. Naqoyquatsi (2002), Godfrey Reggio.

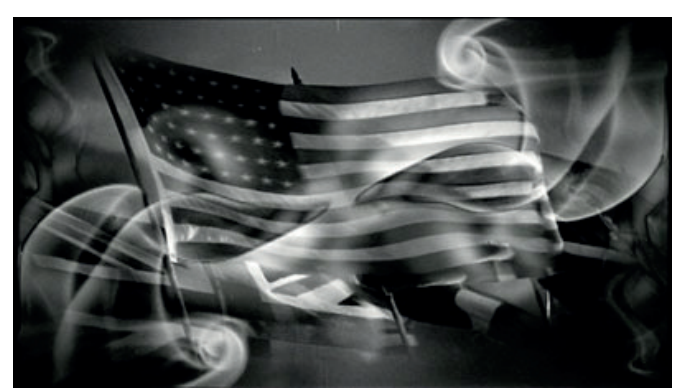

Fonte: https://www.koyaanisqatsi.org/films/naqoyqatsi.php Acesso: 27/10/2017
0 cello assume novamente 0 comando para conduzir as linhas melódicas etéreas de uma quase elegia, que se prolonga pelos episódios Religião, Tempo de mídia e Velho mundo. As investidas do grande capital e seus principais representantes políticos em parques industriais e centros comerciais alternam-se com imagens de cientistas, líderes mundiais de pacificação, personalidades que marcaram o século XX com missões sociais. Fecha-se o episódio com animais em deslocamento na floresta - todos em imagens digitais.

0 tempo intensivo emerge com um forte contraponto que "chicoteia" ${ }^{4}$ os sentidos e novamente 0 frenesi do zoom out arremessa fluxos de imagens para a frente da tela. Ressoa um canto lírico feminino sobreposto aos arquivos de imagens de explosões atômicas digitalizadas marcadas por deslocamentos em superfícies sem gravidade. A paisagem lunar, os chuviscos de raios cósmicos e as reencenações de corpos flutuantes no vazio do espaço relembram as criações pioneiras de Stanley Kubrick, compondo as sequências finais de Ponto cego e Vivência desconhecida. 
Figura 11: Fotograma de um corpo humano no espaço vazio. Naqoyquatsi (2002), Godfrey Reggio.

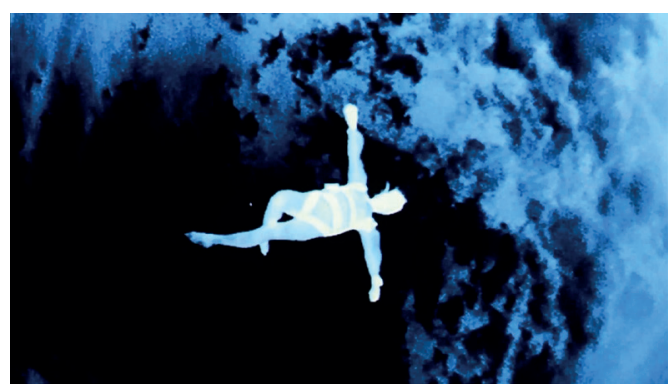

Fonte: https://www.koyaanisqatsi.org/films/naqoyqatsi.php Acesso: 27/10/2017

Contrariamente à valsa gloriosa de Strauss no filme de Kubrick, o cello de Yo-Yo Ma recupera sequências anteriores e se retroalimenta com seus próprios acordes até 0 final, quando a tela com a palavra Naqoyqatsi, título do filme, retorna, agora como verbete de um dicionário. A peça musical continua num crescendo à medida que os créditos avançam e continuam a ecoar sua resposta até o final marcado pela volta do canto operístico do início seguido do acorde orquestral em que se define 0 significado de quatsi na língua hopi.

Naqoyqatsi emerge, assim, de uma movimentação rítmica não restrita à articulação das imagens visuais, mas extensiva ao universo sonoro de um espaço ressonante em que a música não é trilha, mas dimensão pela qual as imagens visuais circulam, se articulam e se retroalimentam na virtualidade de células rítmicas e da combinatória de imagens dos arquivos visuais. Graças ao processo de retroalimentação, 0 espaço cinemático emerge no movimento de sua construção no espaço da tela como processo e não como resultado de uma articulação prévia.

Com isso, observa-se que, em vez de mera repetição, os gestos gráficos operam combinações aleatórias resultantes de diferentes operações de cálculos organizados em arquivos de sons, de imagens, de possibilidades de movimento. Além disso, o encadeamento das imagens tornase muito mais fluido a ponto de projetar uma nova espacialidade, próxima das flutuações em "espaços vazios", onde corpos e objetos parecem libertos da gravidade, sem coordenadas, sem perspectiva, sem pontos de referência. Um espaço de pura virtualidade, em que a persistência do cinema se transforma, de fato, em resistência, em reação de intervenção nos códigos. Emerge assim uma capacidade do cinema que, ao construir um espaço acústico audiovisual e cinético, revela seu mecanismo de retroalimentação e de ressonância.

\section{Considerações finais}

Os experimentos de análise e as inferências produzidos em nossa investigação sobre a plasticidade das imagens audiovisuais no espaço acústico ressonante concentraram suas formulações no convívio do cinema com o entorno cultural. A plasticidade de sua performance tornou-se procedimento fundamental do intercâmbio inibidor de qualquer tipo de dominante. Se, por um lado, seguiu a escalada da eletrificação da cultura por meio de planos rítmicos de formas luminosas, reverberando em 
telas nos mais diferentes espaços da cultura, por outro, continua renovando constantemente sua persistência como arte da ressonância que foi capaz de criar seus precursores, nos termos formulados por Jorge Luís Borges (1952).

Entender a condição ressonante do cinema significa reconhecer seu potencial de lançar luz sobre experiências audiovisuais do passado e do futuro numa onda reverberante, ao mesmo tempo em que preserva a persistência de sua condição como sistema cultural de criação estética. Se reconhecemos a ressonância em relação ao passado, por que não admitir a ressonância que reverbera em criações futuras? Afinal, a radicalidade da experiência audiovisual consolidou a reverberação de formas luminosas nas mais distintas práticas culturais, não apenas da arte, mas do entretenimento, das telecomunicações, da medicina, consagrando o cinema como "filho do tempo e da máquina" (XAVIER, 1994, p. 359). Um filho que cresceu e já reproduziu seus frutos em videografias que não hesitam em radicalizar a experiência audiovisual da transdução do som e da luz de formas elétricas, garantindo uma persistência que não se limita ao fato de as câmeras cinematográficas conservarem 0 regime escópico do registro óptico-perspéctico, como quer D. Rodowick (2007), mas, sim, de ter a capacidade de se transduzir em sonares, em filmes que são movimentos de imagens audiovisuais plasticamente elaboradas pelo sensório técnico e humano.

\section{Referências}

BERENDT, J.E. The Third Ear: on Listening to the

World. Shaftsbury: Element Books.

BORGES, Jorge Luis. Kafka e seus precursores (1951).

In: Outras inquisiciones (1952). Obras completas. São Paulo: Companhia das Letras, 1999.

BULL, M.; BACK, L. The Auditory Culture Reader. Oxford: Berg, 2003.

CHARNEY, L.; SCHWARZ, R. 0 cinema e a invenção da vida moderna. São Paulo: Cosac\&Naif, 2001.

COSTA, Fernando M. Teorias sobre a voz nas décadas de 1960 e 1970 e cinema contemporâneo. Revista

Novos Olhares, São Paulo, v. 6, n. 2, p. 22-29, 2017.

CRARY, Jonathan. Techniques of the Observer. Cambridge: MIT, 1992.

DELEUZE, Gilles. A imagem-tempo. São Paulo: Brasiliense, 2005.

DOANE, Mary. The Emergence of Cinematic Time. Cambridge: Harvard University Press, 2002.

DROBNICK, J. Aural Cultures. Alberta: YYZ Books, 2004.

EISENSTEIN, Sergei. The Synchronization of Senses. In: The Film Sense. Orlando: Harcourt Brace \& Company, 1975.

ERLMANN, V. Hearing Cultures. Essays on Sound, Listening and Modernity. Oxford: Berg, 2004. . Reason and Resonance. A History of Modern Aurality. New York: Zone Books, 2010.

FLUSSER, Vilem. 0 mundo codificado. São Paulo: Cosac\&Naif, 2007.

GILROY, Paul. 0 Atlântico Negro. São Paulo: Ed.34, 2001.

G00DY, Jack; WATT, Ian. The Consequences of Literacy. In: Perspectives on Literacy. E.R. Kintgen ET all, 
Eds. Carbondale and Edwardsville: Southern Illinois University Press, 1988.

GUSMÁN, P. Nostalgie de la lumière. Alemanha-ChileEspanha-França. Direção: Patricio Guzmán, 2010. Documentário. Duração 90 minutos.

HANSEN, Miriam Bratu. Cinema and Experience. Berkeley: University of California Press, 2012.

IHDE, Don. Listening and Voice Phenomenologies of Sound. Albany: State University of New York Press, 2007. . Technology and Lifeworld: From Garden

to Earth. Bloomington: Indiana University Press, 1990. KITTLER, Friedrich. Towards an Ontology of Media. Theory Culture Society (2006), vol 26: 23. (PDF)

LOPES, José de Souza Miguel. Cultura acústica e memória em Moçambique: as marcas indeléveis numa antropologia dos sentidos. Scripta. Belo Horizonte, v. 4, n.8, p. 208-228, 2001.

LOTMAN, Yuri. Universe of the Mind. A Semiotic Theory of Culture. Bloomington and Indianapolis: Indiana University Press, 1990.

MACHADO, Irene. Memória informacional da cultura no contexto da metalinguagem crítica de Lótman. Revista FAMECOS: mídia, cultura, tecnologia. Porto Alegre, v. 23, n. $2,2016$.

. Sensus communis: para entender 0

espaço acústico e seu ambiente sensorial ressonante.

E-Compós. Revista dos Programas de Pós-graduação em Comunicação. Brasília, v. 14, n. 3, 2011.

McLUHAN, Erick. The Sensus Communis.

Synesthesia, and the Soul: An Odyssey. Toronto: Bastian Publishing, 2015.

McLUHAN, M. (1977). A galáxia de Gutenberg. A formação do homem tipográfico (trad. Leônidas G. de Carvalho e Anísio Teixeira). São Paulo: Cia. Editora Nacional, 1977.
McLUHAN, M.; POWERS, B.R. La aldea global.

Barcelona: Gedisa, 1989.

McLUHAN, L.; FIORE, Q. The Medium is the Message: An Inventory of Effects. 1969.

MICHELSON, A. Kino-eye. The Writings of Dziga

Vertov. Berkeley: University of Califórnia Press, 1984.

MIDOLO, E. D. Sound Matters. Orizzonti sonori della cultura contemporânea. Milano: Vita e Pensioero, 2007.

ONG, Walter. Oralidade e cultura escrita. Campinas: Papirus, 1998.

ONG, Walter J. Interfaces of the Word. Studies in the Evolution of Consciousness and Culture. Ithaca and London: Cornell University Press, 1977.

. The Presence of the Word. Some

Prolegomena for Cultural and Religious History. Minneapolis: University of Minnesota Press, 1967.

. Rhetoric, Romance, and Technology. Studies in the Interaction of Expression and Culture. Ithaca and London: Cornell University Press, 1971.

RODOWICK, D.N. The Virtual Life of Film. Cambridge: Harvard University Press, 2007.

SEBEOK, Thomas. Comunicação. In: Comunicação na era pós-moderna (Mônica Rector \& Eduardo Neiva, orgs.). Petrópolis: Vozes, 1997.

SEIÇA, Álvaro. Transdução: Processos de Transferência na Literatura Electrónica e Arte Digital. Edições Húmus, 2017.

SHAVIRO, Shaviro. 0 corpo cinemático. São Paulo: Paulus, 2015.

SOBCHACK, Vivian. Carnal Thoughts. Embodiment and Moving Image Culture. Berkeley: University of California Press, 2004.

SODRÉ, Muniz. As estratégias sensíveis: afeto, mídia e política. Rio de Janeiro: Vozes, 2006. 
STERNE, Jonathan. Machines to Hear for Them. The Audible Past: Cultural Origins of Sound Reproduction. Durhan: Duke Univesity Press, p. 13-85, 2003.

XAVIER, Ismail. Eisenstein. A construção do pensamento por imagens. In: Artepensamento, Adauto Novaes, org. São Paulo: Companhia das Letras, 1994.

XAVIER, Ismail org. A experiência do cinema. Rio de Janeiro: Graal, 1983.

\section{Filmografia}

ENTHUSIASM: The Symphony Donbass (Entuziazm: Simfonya Donbassa). Direção: Dziga Viértov. Música: D. Chostakovich. Edição: E. Svilova. Produção: Ukrainfilm. URSS, 1930. $65 \mathrm{~min}$.

Disponível em https://vimeo.com/87904802. Acesso: 15/11/2017.

GLOBAL Groove. Direção: Nam June Paik and John Godfrey. EUA, 1973.

Disponível em https://www.youtube.com/ watch?v=GWhpH_w77fk. Acesso: 01/11/2017.

NAQOYQATSI. Life as War. Direção: Godfrey Reggio. Música: Philip Glass. Intérprete: Yo-Yo Ma. Produção: Miramax Films and Steven Soderbergh. EUA, 2002. DVD (1h29min).

TERRA em transe. Direção: Glauber Rocha. Edição: Eduardo Escorel. Música: Sérgio Ricardo. Fotografia: Luis Carlos Barreto. Produtores associados: Luis Carlos Barreto e Carlos Diegues. Brasil, 1967. DVD (115min).

UM HOMEM com a câmera (Tchelovek s kinoapparatom). Direção: Dziga Viértov. Fotografia: Mikhail Kaufmann. Montagem: E. Svilova. Produção: VUFKU (Kiev). URSS, 1929. DVD (68 min). Trilha sonora: Alloy Orchestra. 


\begin{tabular}{|c|c|}
\hline $\begin{array}{l}\text { Plasticity of audiovisual } \\
\text { images in the acoustic-resonant } \\
\text { space of cinema }\end{array}$ & $\begin{array}{l}\text { Plasticidad de las imágenes } \\
\text { audiovisuales en el espacio } \\
\text { acústico-resonante del cine }\end{array}$ \\
\hline $\begin{array}{l}\text { Abstract } \\
\text { This essay examines the relationship between space } \\
\text { and communication in audiovisual media under } \\
\text { the scopic regime dominant disregarding sound } \\
\text { objects. The realignment of the role of sound in the } \\
\text { audiovisual definition of culture is demanded, in } \\
\text { order to review the importance of the acoustic-sound } \\
\text { dimension. For this, the essay's main hypothesis } \\
\text { recognizes that cinema plays a crucial role in the } \\
\text { renewal of the relationship between sound and } \\
\text { noise, especially with respect to the consolidation } \\
\text { of the acoustic-resonant space in electric media. } \\
\text { Therefore, it is understood that sound materials are } \\
\text { as determinant of audiovisual images as visuality, as } \\
\text { can be seen in comparative film analysis. It is hoped } \\
\text { to recover the legacy of the acoustic cultures now } \\
\text { reprocessed in terms of audiovisual experience of } \\
\text { electronic-digital character. } \\
\text { Keywords } \\
\text { Audiovisual culture. Acoustic space. Resonance. }\end{array}$ & $\begin{array}{l}\text { Resumen } \\
\text { El presente ensayo examina la relación entre } \\
\text { espacio y comunicación en los medios audiovisuales } \\
\text { marcada por la dominación del régimen escópico } \\
\text { en detrimento de los objetos sonoros. Se reclama } \\
\text { el realineamiento del papel del sonido en la } \\
\text { definición audiovisual de la cultura, a fin de revisar } \\
\text { la importancia de la dimensión sonoro-acústica. } \\
\text { Para ello, la hipótesis de fondo reconoce que el } \\
\text { cine tiene un papel decisivo en la renovación de la } \\
\text { relación del sonido con el ruido, sobre todo en lo que } \\
\text { se refiere a la consolidación del espacio acústico- } \\
\text { resonante creado por los medios eléctricos. Por lo } \\
\text { tanto, entiende que las materias sonoras son tan } \\
\text { determinantes de las imágenes audiovisuales como } \\
\text { la visualidad, como se puede averiguar en los análisis } \\
\text { fílmicos comparativos. Se espera, con el análisis, } \\
\text { rescatar el legado de los cultivos acústicos ahora } \\
\text { reprocesados en términos de experiencia audiovisual } \\
\text { de carácter electrónico-digital. } \\
\text { Palabras-clave } \\
\text { Cultura audiovisual. Espacio acústico. Resonancia. }\end{array}$ \\
\hline
\end{tabular}




\section{Expediente}

A revista E-Compós é a publicação científica em formato eletrônico da Associação Nacional dos Programas de Pós-Graduação em Comunicação (Compós). Lançada em 2004, tem como principal finalidade difundir a produção acadêmica de pesquisadores da área de Comunicação, inseridos em instituições do Brasil e do exterior.

\section{E-COMPÓS I www.e-compos.org.br I E-ISSN 1808-2599}

Revista da Associação Nacional dos Programas de Pós-Graduação em Comunicação. Brasília, v.21, n.1, jan./abr. 2018. A identificação das edições, a partir de 2008 , passa a ser volume anual com três números. Indexada por Latindex I www.latindex.unam.mx

\section{CONSELHO EDITORIAL}

Ada Cristina Machado Silveira, Universidade Federal de Santa Maria, Brasil Alda Cristina Silva da Costa, Universidade Federal do Pará, Brasil Alfredo Luiz Paes de Oliveira Suppia, Universidade Estadual de Campinas, Brasil Ana Regina Barros Rego Leal, Universidade Federal do Piauí, Brasil Ana Carolina Rocha Pessôa Temer, Universidade Federal de Goiás, Brasil André Luiz Martins Lemos, Universidade Federal da Bahia, Brasil Angela Cristina Salgueiro Marques, Universidade Federal de Minas Gerais, Brasil Ângela Freire Prysthon, Universidade Federal de Pernambuco, Brasil Antonio Carlos Hohlfeldt, Pontifícia Universidade Católica do Rio Grande do Sul, Brasil Arthur Ituassu, Pontifícia Universidade Católica do Rio de Janeiro, Brasil

Bruno Campanella, Universidade Federal Fluminense, Brasil

Cláudio Novaes Pinto Coelho, Faculdade Cásper Líbero, Brasil Cárlida Emerim, Universidade Federal de Santa Catarina, Brasil Carlos Eduardo Franciscato, Universidade Federal de Sergipe, Brasil Danilo Rothberg, Universidade Estadual Paulista, Brasil Denise Tavares da Silva, Universidade Federal Fluminense, Brasil Diógenes Lycarião, Universidade Federal do Ceará, Brasil Eduardo Vicente, Universidade de São Paulo, Brasil Eliza Bachega Casadei, Escola Superior de Propaganda e Marketing - SP, Brasil Eneus Trindade, Universidade de São Paulo, Brasil

Erick Felinto de Oliveira, Universidade do Estado do Rio de Janeiro, Brasil Erly Vieira Júnior, Universidade Federal do Espírito Santo, Brasil Francisco de Assis, FIAM-FAAM Centro Universitário, Brasi

Francisco Elinaldo Teixeira, Universidade Estadual de Campinas, Brasi Francisco Gilson R. Pôrto Jr., Universidade Federal do Tocantins, Brasil Frederico de Mello Brandão Tavares, Universidade Federal de Ouro Preto, Brasil Gabriela Reinaldo, Universidade Federal do Ceará, Brasil Gilson Vieira Monteiro, Universidade Federal do Amazonas, Brasil Gustavo Daudt Fischer, Universidade do Vale do Rio dos Sinos, Brasi Itania Maria Mota Gomes, Universidade Federal da Bahia, Brasil Jiani Adriana Bonin, Universidade do Vale do Rio dos Sinos, Brasil José Afonso da Silva Junior, Universidade Federal de Pernambuco, Brasil José Luiz Aidar Prado, Pontifícia Universidade Católica de São Paulo, Brasil Josette Maria Monzani, Universidade Federal de São Carlos, Brasi Juçara Gorski Brittes, Universidade Federal de Ouro Preto, Brasil
Juliana Freire Gutmann, Universidade Federal da Bahia, Brasil Laura Loguercio Cánepa, Universidade Anhembi Morumbi, Brasil Leonel Azevedo de Aguiar, Pontifícia Universidade Católica do Rio de Janeiro, Brasil Letícia Cantarela Matheus, Universidade do Estado do Rio de Janeiro, Brasil Luciana Coutinho Souza, Universidade de Sorocaba, Brasil Maria Ataide Malcher, Universidade Federal do Pará, Brasil Maria Elisabete Antonioli, Escola Superior de Propaganda e Marketing - SP, Brasil Maria das Graças Pinto Coelho, Universidade Federal do Rio Grande do Norte, Brasil Marialva Carlos Barbosa, Universidade Federal do Rio de Janeiro, Brasil Marcel Vieira Barreto Silva, Universidade Federal da Paraíba, Brasil Marcia Tondato, Escola Superior de Propaganda e Marketing, Brasil Marli Santos, Universidade Metodista de São Paulo, Brasil

Márcio Souza Gonçalves, Universidade do Estado do Rio de Janeiro, Brasil Mauricio Mario Monteiro, Universidade Anhembi Morumbi, Brasil Mayka Castellano, Universidade Federal Fluminense, Brasil

Mozahir Salomão Bruck, Pontifícia Universidade Católica de Minas Gerais, Brasil Nisia Martins Rosario, Universidade Federal do Rio Grande do Sul, Brasil Paolo Demuru, Universidade Paulista, Brasil

Paula Melani Rocha, Universidade Estadual de Ponta Grossa, Brasil Potiguara Mendes Silveira Jr, Universidade Federal de Juiz de Fora, Brasil Priscila Ferreira Perazzo, Universidade Municipal de São Caetano do Sul, Brasil Rafael Cardoso Sampaio, Universidade Federal do Paraná, Brasil Rafael Tassi Teixeira, Universidade Tuiuti do Paraná, Brasil Regiane Lucas Garcês, Universidade Federal de Minas Gerais, Brasil Regiane Regina Ribeiro, Universidade Federal do Paraná, Brasil Renata Pitombo Cidreira, Universidade Federal do Recôncavo da Bahia, Brasil Renato Essenfelder, Escola Superior de Propaganda e Marketing, Brasil Roberto Elísio dos Santos, Universidade Municipal de São Caetano do Sul, Brasil Rodolfo Rorato Londero, Universidade Estadual de Londrina, Brasil Roseli Figaro, Universidade de São Paulo, Brasil

Simone Maria Andrade Pereira de Sá, Universidade Federal Fluminense, Brasil Sofia Cavalcanti Zanforlin, Universidade Católica de Brasília, Brasil Sônia Caldas Pessoa, Universidade Federal de Minas Gerais, Brasil Tatiana Oliveira Siciliano, Pontifícia Universidade Católica do Rio de Janeiro, Brasil Thaïs de Mendonça Jorge, Universidade de Brasília, Brasil

Valquiria Michela John, Universidade Federal do Paraná, Brasil

\section{CONSELHO CIENTÍFICO}

Cristiane Freitas Gutfreind, Pontifícia Universidade Católica do Rio Grande do Sul, Brasil | Eduardo Antônio de Jesus, Universidade Federal de Minhas Gerais, Brasil I Eduardo Morettin, Universidade de São Paulo, Brasil I Irene de Araújo Machado, Universidade de São Paulo, Brasil I Miriam de Souza Rossini, Universidade Federal do Rio Grande do Sul, Brasil

\section{COMISSÃO EDITORIAL}

Igor Pinto Sacramento, Universidade Federal do Rio de Janeiro, Brasil I Kelly Cristina de Souza Prudencio, Universidade Federal do Paraná, Brasil I Osmar Gonçalves dos Reis Filho, Universidade Federal do Ceará, Brasil I Rafael Grohmann, Faculdade Cásper Líbero, Brasil I Thaiane Moreira de Oliveira, Universidade Federal Fluminense, Brasil (editores associados)

\section{CONSULTORES AD HOC}

Afonso de Albuquerque, Universidade Federal Fluminense, Brasil I Cláudia Lago, Universidade de São Paulo, Brasil I Cesar Baio Santos, Universidade Federal do Ceará, Brasil I Eduardo Pellanda, Pontifícia Universidade Católica do Rio Grande do Sul, Brasi | Francisco Rüdiger, Pontifícia Universidade Católica do Rio Grande do Sul, Brasil | Karina Woitowicz, Universidade Estadual de Ponta Grossa, Brasil I Luis Mauro Sa Martino, Faculdade Cásper Líbero, Brasil I Norval Baitello Jr, Pontifícia Universidade Católica de São Paulo, Brasil I Pedro Guimarães, Universidade de Campinas, Brasil

\section{EQUIPE TÉCNICA}

ASSISTENTES EDITORIAIS Márcio Zanetti Negrini e Melina Santos । REVISÃO DE TEXTOS Fátima Áli | EDITORAÇ̃̃O ELETRÔNICA Roka Estúdio
COMPÓS I www.compos.org.br

Associação Nacional dos Programas de Pós-Graduação em Comunicação

Presidente

Marco Roxo

Programa de Pós-Graduação em Comunicação - UFF marcos-roxo@uol.com.br

Vice-Presidente

Isaltina Gomes

Programa de Pós-Graduação em Comunicação - UFPE

isaltina@gmail.com

Secretária-Geral

Gisela Castro

Programa de Pós-Graduação em Comunicação

e Práticas de Consumo - ESPM

castro.gisela@gmail.com

CONTATO I revistaecompos@gmail.com 